\title{
Oxidative stress response genes in Mycobacterium tuberculosis: role of ahpC in resistance to peroxynitrite and stage-specific survival in macrophages
}

\author{
S. S. Master ${ }^{1}$, B. Springer ${ }^{3}$, P. Sander ${ }^{3}$, E. C. Boettger ${ }^{4}$, V. Deretic ${ }^{1}$ \\ and G. S. Timmins ${ }^{2}$
}

Author for correspondence: V. Deretic. Tel: +1 505272 0291. Fax: +1 5052726029. e-mail: vderetic@salud.unm.edu

1,2 Department of Molecular Genetics and Microbiology ${ }^{1}$ and Department of Pharmacy ${ }^{2}$, University of New Mexico Health Sciences Center 915 Camino de Salud, Albuquerque, NM 87131, USA

3 Institute for Medical Microbiology, Medizinische Hochschule, 30625, Hannover, Germany

4 Institute of Medical Microbiology, University of Zurich, $\mathrm{CH}-8028$ Zurich, Switzerland

\begin{abstract}
The Mycobacterium tuberculosis ahpC gene, encoding the mycobacterial orthologue of alkylhydroperoxide reductase, undergoes an unusual regulatory cycle. The levels of AhpC alternate between stages of expression silencing in virulent strains grown as aerated cultures, secondary to a natural loss of the regulatory oxy $R$ function in all strains of the tubercle bacillus, and expression activation in static bacilli by a yet undefined mechanism. The reasons for this unorthodox regulatory cycle controlling expression of an antioxidant factor are currently not known. In this work, M. tuberculosis H37Rv and Mycobacterium smegmatis mc $^{2} 155$ ahpC knockout mutants were tested for sensitivity to reactive nitrogen intermediates, in particular peroxynitrite, a highly reactive combinatorial product of reactive nitrogen and oxygen species, and sensitivity to bactericidal mechanisms in resting and activated macrophages. Both $M$. tuberculosis ahpC:: $\mathrm{Km}^{\mathrm{r}}$ and $M$. smegmatis ahpC:: Km ${ }^{r}$ showed increased susceptibility to peroxynitrite. In contrast, inactivation of ahpC in $M$. tuberculosis did not cause increased sensitivity to donors of NO alone. M. tuberculosis ahpC:: $\mathrm{Km}^{\mathrm{r}}$ also showed decreased survival in unstimulated macrophages, but the effect was no longer detectable upon IFN $\gamma$ activation. These studies establish a specific role for ahpC in antioxidant defences involving peroxynitrite and most likely additional cidal mechanisms in macrophages, with the regulatory cycle likely contributing to survival upon coming out of the stationary phase during dormancy (latent infection) or upon transmission to a new host.
\end{abstract}

Keywords: M. tuberculosis, nitric oxide, ahpC, peroxynitrite, latency

\section{INTRODUCTION}

Peroxynitrite $\left(\mathrm{ONOO}^{-}\right)$and other reactive nitrogen and oxygen intermediates produced by macrophages play a role in host defence against invading bacteria (Akaki et al., 2000; Darrah et al., 2000; Karupiah et al., 2000; Nathan \& Shiloh, 2000; Paziak-Domanska et al., 2000; Shiloh \& Nathan, 2000; Yu et al., 1999). Consequently, many bacterial pathogens have evolved protection mechanisms against reactive oxygen and nitrogen intermediates (Zahrt \& Deretic, 2002). In myco-

Abbreviations: DETA nonoate, (Z)-1-[N-(2-aminoethyl)- $N$-(2-ammonioethyl)aminio]diazen-1-ium-1,2-diolate). bacteria, the kat $G$ and $a h p C$ genes are the best studied factors from this class. The kat $G$ locus is genetically linked to the furA gene (Deretic et al., 1997; PaganRamos et al., 1998), which encodes a homologue of the ferric uptake regulator (Baillon et al., 1999; Bsat et al., 1998; Dubrac \& Touati, 2000; Hassett et al., 1997; Lee et al., 1998; Niederhoffer et al., 1990; Tardat \& Touati, 1993; van Vliet et al., 1998, 1999; Zheng et al., 1999). Interestingly, the locus encompassing fur $A$ and $k a t G$ has been inactivated in Mycobacterium leprae, but has been preserved in all other mycobacteria (Cole, 1998; Deretic et al., 1997; Nakata et al., 1997; Pagan-Ramos et al., 1998). Previous studies in our laboratory indicate that FurA negatively regulates KatG expression in mycobacteria (Zahrt et al., 2001), and that there exists a dual and 
stage-specific induction of the two kat $G$ promoters (Master et al., 2001). The kat G gene encodes a catalaseperoxidase (Heym et al., 1993), which in vitro has peroxynitritase and additional redox activities (Heym et al., 1993; Magliozzo \& Marcinkeviciene, 1997; Wengenack et al., 1999) and has been shown to play a role in the virulence of M. tuberculosis (Cooper et al., 2000; Li et al., 1998; Manca et al., 1999; Middlebrook \& Kohn, 1953; Mitchison et al., 1963; Morse et al., 1954; Wilson et al., 1995). The mycobacterial ahpC gene encodes an orthologue of bacterial alkyl hydroperoxidases (Chen et al., 1998; Christman et al., 1985; Cooper et al., 2000; Dhandayuthapani et al., 1996; Heym et al., 1997; Jacobson et al., 1989; Pagan-Ramos et al., 1998; Sherman et al., 1996; Springer et al., 2001; Sreevatsan et al., 1997; Wilson et al., 1998). In most mycobacteria, the $a h p C$ gene is linked to oxyR and is activated by its gene product, an orthologue of the global regulator OxyR, controlling the peroxide stress response in bacteria (Aslund et al., 1999; Christman et al., 1985; Storz \& Altuvia, 1994). In M. tuberculosis as a species, and in all members of the M. tuberculosis complex, the $o x y R$ gene is inactivated and represents a pseudogene (Deretic et al., 1995, 1997). Recently, we have shown that there exists a second level of $a h p C$ regulation independent of $o x y R$ (Springer et al., 2001). The $a b p C$ gene is silenced in aerobic cultures of virulent M. tuberculosis, but is activated in statically grown organisms (Springer et al., 2001). AhpC has been indirectly implicated in nitric oxide metabolism using expression in heterologous systems like Salmonella (Chen et al., 1998). Purified AhpC has been shown to reduce hydroxyperoxide radicals (Chauhan \& Mande, 2001; Hillas et al., 2000) and has also been suggested to have peroxynitritase activity (Bryk et al., 2000), but no direct analyses in mycobacteria have been carried out thus far.

Here, we continued our investigations of the role of ahpC in $M$. tuberculosis biology, specifically with respect to its proposed role in resistance to reactive nitrogen species and survival in macrophages. Using knockout strains of $a h p C\left(a h p C:: \mathrm{Km}^{\mathrm{r}}\right)$ in M. tuberculosis (Springer et al., 2001) and M. smegmatis (Dhandayuthapani et al., 1996), we compared the wildtype strains and their $a h p C$ mutant derivatives for survival upon exposure to compounds producing reactive nitrogen intermediates and during infection of resting and activated macrophages.

\section{METHODS}

Bacterial strains. M. smegmatis $\mathrm{mc}^{2} 155$ strains $a h p C^{+}$(wildtype), ahpC:: Km ${ }^{\mathrm{r}}$ (VD1865-6; Dhandayuthapani et al., 1996) and furA:: Km ${ }^{\mathrm{r}}$ (JS106-1; Zahrt et al., 2001), and M. tuberculosis $\mathrm{H} 37 \mathrm{Rv}_{\mathrm{Str}}{ }^{\mathrm{r}}$ strains ahp $\mathrm{C}^{+}$(RvTAM1424, wild-type) and $a h p C:: \mathrm{Km}^{\mathrm{r}}$ (RvTAM1424-1-1; Springer et al., 2001) were constructed previously and the specificity of the mutations confirmed by genetic complementation (Dhandayuthapani et al., 1996; Springer et al., 2001; Zahrt et al., 2001).

Media and growth conditions. The strains were grown until mid-exponential phase and/or stationary phase (as indicated) on $7 \mathrm{H} 9$ (Difco) or $7 \mathrm{H} 11$ plates, supplemented with $0.5 \%$ Tween, $0 \cdot 2 \%$ glycerol and OADC (oleic acid, $10 \%$ bovine serum fraction $\mathrm{V}$, glucose and catalase). Bacteria were grown at $37^{\circ} \mathrm{C}$. All manipulations of live M. tuberculosis were carried out under Biosafety Level 3 conditions.

Chemicals. Both peroxynitrite and DETA nonoate $\{(\mathrm{Z})-1-[N-$ (2-aminoethyl)-N-(2-ammonioethyl)aminio]diazen-1-ium-

1,2-diolate)\} were purchased from Alexis Corporation.

Detection of lipid peroxides. Lipid peroxides were detected using FOX II reagent, which provides a sensitive colorimetric assay for peroxides measured spectrophotometrically at $560 \mathrm{~nm}$. FOX II reagent contains $90 \%$ methanol, $25 \mathrm{mM}$ $\mathrm{H}_{2} \mathrm{SO}_{4}, 250 \mu \mathrm{M}$ ferrous sulfate heptahydrate (Sigma) and $100 \mu \mathrm{M}$ xylene orange (Sigma) (Jiang et al., 1992; NouroozZadeh et al., 1994; Wolff et al., 1994). M. smegmatis $\mathrm{mc}^{2} 155$ strains $a h p C^{+}$(wild-type), $a h p C:: \mathrm{Km}^{\mathrm{r}}$ and fur $A:: \mathrm{Km}^{\mathrm{r}}$ were grown until mid-exponential phase. These cultures were then exposed to $1 \mathrm{mM}$ peroxynitrite for five $3 \mathrm{~min}$ cycles at $37^{\circ} \mathrm{C}$. One-hundred microlitres of the treated culture was incubated for 10 min with $900 \mu \mathrm{l} \mathrm{FOX} \mathrm{II} \mathrm{reagent} \mathrm{to} \mathrm{allow} \mathrm{the} \mathrm{reaction} \mathrm{of}$ peroxides. Experiments were carried out in triplicate and results quantified using a standard curve created with hydrogen peroxide

Sensitivity assays and survival in macrophages. M. tuberculosis $\mathrm{H} 37 \mathrm{Rv} a h p C^{+}$and $a h p C:: \mathrm{Km}^{\mathrm{r}}$ were allowed to reach stationary phase. Similarly, M. smegmatis $\mathrm{mc}^{2} 155$ strains ahp $C^{+}$(wild-type), ahpC:: $\mathrm{Km}^{\mathrm{r}}$ and fur $A:: \mathrm{Km}^{\mathrm{r}}$ were grown until mid-exponential or stationary phase. These cultures were then exposed to various concentrations of peroxynitrite and DETA nonoate or used to infect J774A macrophages at an m.o.i. of 10:1 in the presence or absence of $\operatorname{IFN} \gamma\left(500 \mathrm{U} \mathrm{ml}^{-1}\right)$ and LPS $\left(125 \mathrm{ng} \mathrm{ml}^{-1}\right)$. The results of treatment with these compounds and macrophage infections were assessed by plating and c.f.u. determination.

\section{RESULTS AND DISCUSSION}

\section{Role of ahpC in mycobacterial survival against reactive nitrogen intermediates}

M. smegmatis $\mathrm{mc}^{2} 155$ strains $a h p C^{+}$(wild-type),

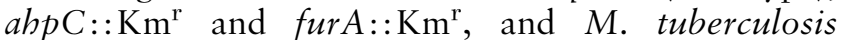
$\mathrm{H} 37 \mathrm{Rv} \operatorname{Str}^{\mathrm{r}}$ strains $a h p C^{+}$(wild-type) and $a h p C:: \mathrm{Km}^{\mathrm{r}}$ were grown until mid-exponential phase and/or stationary phase as indicated. M. smegmatis mid-exponential-phase and stationary-phase cultures were exposed to peroxynitrite using repeated cycles of addition of fresh reagent to the culture (1, 2 and 5 cycles) of $3 \mathrm{~min}$ each at $37^{\circ} \mathrm{C}$ (Fig. 1a). The half-life of peroxynitrite in neutral solution is measured in seconds so a $3 \mathrm{~min}$ exposure is sufficient to ensure its complete consumption. Our results showed increased sensitivity to peroxy-

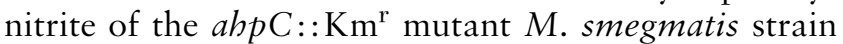
compared to $a h p C^{+}$cells (Fig. $1 \mathrm{a}, \mathrm{b}$ ). In contrast to the ahpC:: $\mathrm{Km}^{\mathrm{r}}$ mutant, another M. smegmatis mutant (furA:: $\mathrm{Km}^{\mathrm{r}}$ ) was as resistant to peroxynitrite as the $a h p C^{+}$(parental) strain. The differential sensitivity to peroxynitrite was observed irrespective of whether the strains were growing exponentially or had entered stationary phase (Fig. 1b). 


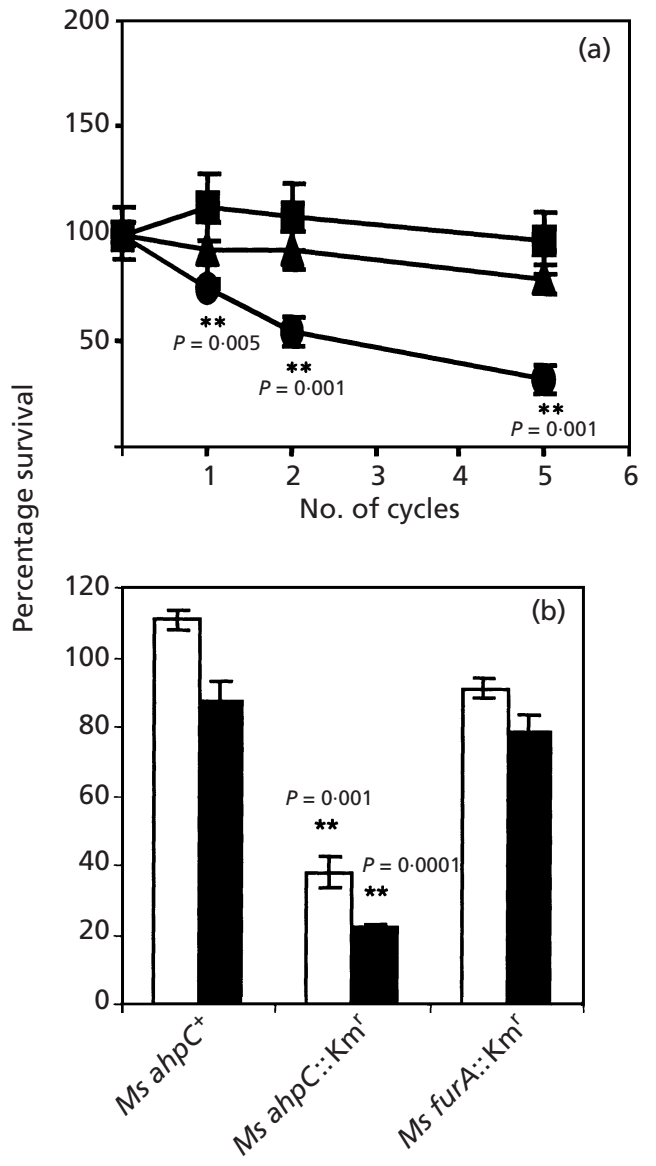

Fig. 1. The $a h p C$ gene is required for full resistance of $M$. smegmatis to peroxynitrite. (a) Survival of mid-exponential phase exponentially growing cultures of $M$. smegmatis $\mathrm{mc}^{2} 155$ $a h p C^{+}(\boldsymbol{\square}), \operatorname{ahpC}:: \mathrm{Km}^{r}(\boldsymbol{O})$ and furA: $: \mathrm{Km}^{\mathrm{r}}(\boldsymbol{\Delta})$ upon exposure to $0.5 \mathrm{mM}$ peroxynitrite for the indicated number of $3 \mathrm{~min}$ cycles. (b) Comparison of mid-exponential-phase ( $\square$ ) and stationary-phase $(\square)$ cultures of $M$. smegmatis $\mathrm{mc}^{2} 155 \mathrm{ahpC^{+ }}$, ahpC:: $\mathrm{Km}^{r}$ and furA:: $\mathrm{Km}^{r}$ exposed to 5 cycles of $1 \mathrm{mM}$ peroxynitrite. Survival is expressed as percentage c.f.u. in untreated controls. **, $P<0.01$ (ANOVA). Actual $P$ values are given below points showing statistically significant differences.

Next, experiments were carried out using M. tuberculosis H37Rv. Since ahpC is not expressed in virulent $M$. tuberculosis grown with aeration (Springer et al., 2001), but is expressed in statically grown cultures, M. tuberculosis $\mathrm{H} 37 \mathrm{Rv}$ ahp $C^{+}$and its $a h p C:: \mathrm{Km}^{\mathrm{r}}$ derivative were grown without aeration as described previously (Springer et al., 2001). Here too, after 5 cycles of peroxynitrite treatment, a significant increase in sensitivity to peroxynitrite was observed in $a h p C:: \mathrm{Km}^{\mathrm{r}}$ mutant cells (Fig. 2a). To test the sensitivity of $M$. tuberculosis $\mathrm{H} 37 \mathrm{Rv}$ strains ahpC $C^{+}$and $a h p C:: \mathrm{Km}^{\mathrm{r}}$ to $\mathrm{NO}$ alone, stationary-phase cultures were exposed to an NO donor, DETA nonoate. No detectable differences in survival were observed between the wild-type and the ahpC:: $\mathrm{Km}^{\mathrm{r}}$ mutant under the conditions tested (Fig. $2 \mathrm{~b})$, although DETA did have an overall inhibitory effect

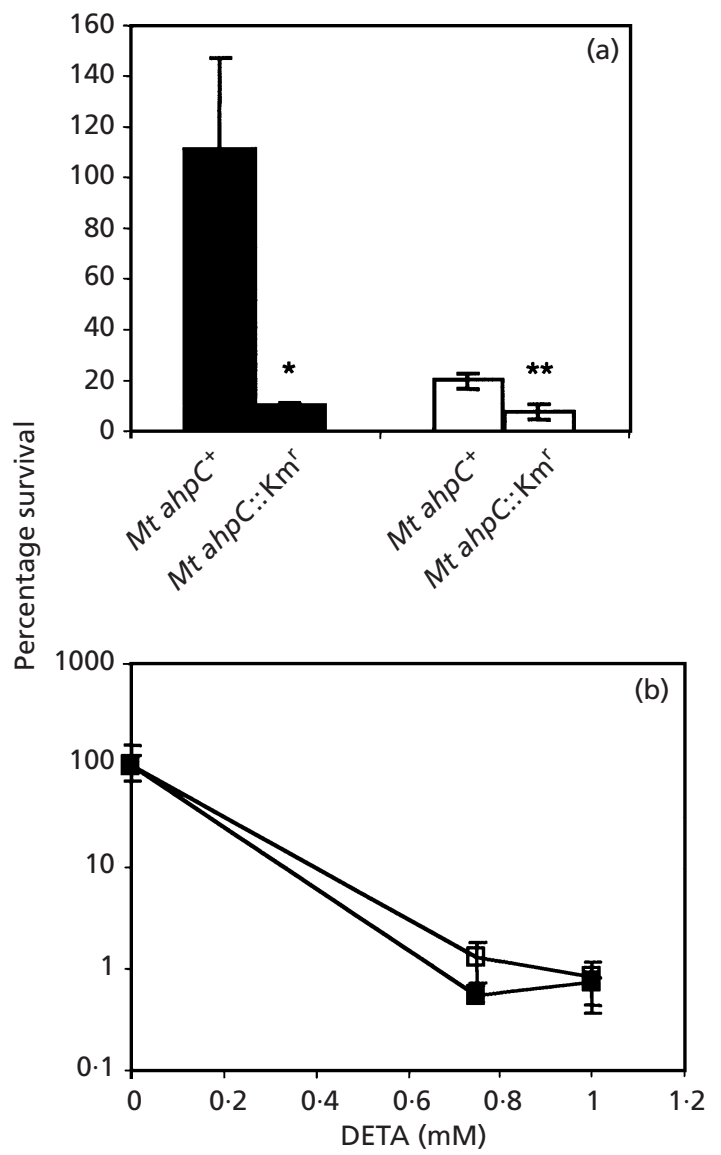

Fig. 2. The $a h p C$ gene is required for full resistance of $M$. tuberculosis H37Rv to peroxynitrite, but not to nitric oxide. (a) Survival of $M$. tuberculosis $\mathrm{H} 37 \mathrm{Rv}$ ahpC $\mathrm{C}^{+}$and $\mathrm{ahpC}:: \mathrm{Km}^{\mathrm{r}}$ upon exposure to $0.5(\square)$ and $1.0 \mathrm{mM}(\square)$ peroxynitrite. (b) Survival of $M$. tuberculosis H37Rv ahpC ${ }^{+}(\square)$ and ahpC:: $\mathrm{Km}^{\mathrm{r}}(\square)$ treated with the NO donor DETA nonoate. Stationary-phase cultures were exposed to the indicated concentrations for five $3 \mathrm{~min}$ cycles (peroxynitrite) or for 3 days (DETA) at $37^{\circ} \mathrm{C}$. Survival is expressed as percentage c.f.u. in untreated cultures. ${ }^{*}, P=0.05$; $* *, P=0.01$ (ANOVA).

on M. tuberculosis, consistent with a mycobactericidal action of NO.

\section{Elevated lipid peroxides in the absence of ahpC}

Peroxynitrite can react to form several oxidizing species that react with lipids to form lipid peroxides (see Fig. 3a). To examine whether differences in lipid peroxidation could be detected among the three M. smegmatis $\mathrm{mc}^{2} 155$ strains, $a h p C^{+}$(wild-type), $a h p C:: \mathrm{Km}^{\mathrm{r}}$ and furA:: $\mathrm{Km}^{\mathrm{r}}$, cultures were treated with peroxynitrite as described in Methods and assayed spectrophotometrically using the FOX II reagent. Our results show that the ahpC:: $\mathrm{Km}^{\mathrm{r}}$ mutant strain produced the maximum amount of lipid peroxides $(P<0 \cdot 5$, ANOVA), while the furA:: $\mathrm{Km}^{\mathrm{r}}$ mutant, which constitutively expresses KatG (Zahrt et al., 2001), produced the least amount of lipid peroxides (Fig. 3b). The correlation observed between these results and the sensitivity of the strains to 
(a)

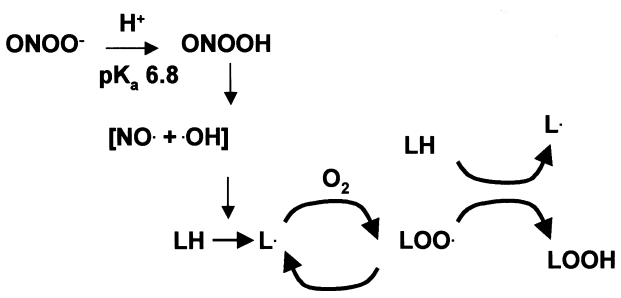

(b)

Ms ahpC $\quad 58 \pm 2$

Ms ahpC:: $\mathrm{Km}^{\mathrm{r}} \quad 63 \pm 2$

Ms furA:: $\mathrm{Km}^{\mathrm{r}} \quad 48 \pm 1$
Fig. 3. Increased production of lipid peroxides in the absence of the ahpC gene. (a) Chemistry of the reaction of peroxynitrite-derived oxidizing species with lipids to form lipid peroxides. (b) Spectrophotometric detection of lipid hydroperoxides on exposure of $M$. smegmatis $\mathrm{mc}^{2} 155 \mathrm{ahpC} \mathrm{C}^{+}$, ahpC:: $\mathrm{Km}^{\mathrm{r}}$ and furA:: $\mathrm{Km}^{\mathrm{r}}$ to $1 \mathrm{mM}$ peroxynitrite for five cycles. Results are expressed as nmol peroxide produced $\pm S E$, quantified using a standard curve generated with hydrogen peroxide.

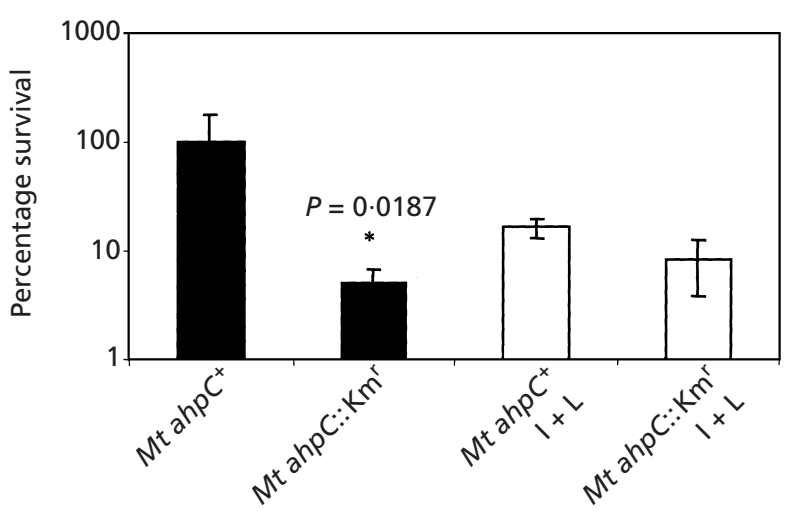

Fig. 4. Decreased survival of $M$. tuberculosis ahpC:: $\mathrm{Km}^{\mathrm{r}}$ after 7 days infection in macrophages. Survival is expressed as percentage c.f.u. obtained with $a h p C^{+}$cells in unstimulated

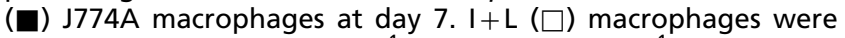
activated with $500 \mathrm{U}$ IFN $\gamma \mathrm{ml}^{-1}$ and $125 \mathrm{ng} \mathrm{LPS} \mathrm{ml}^{-1}$.

peroxynitrite (compare Fig. 1 with Fig. 3.) suggests that lipid peroxidation levels correlate with the killing of mycobacteria. These results indicate that $\mathrm{AhpC}$ protects mycobacteria from the deleterious effects of peroxynitrite-induced oxidation.

\section{Role of AhpC in M. tuberculosis survival during macrophage infection}

Statically grown cultures of $M$. tuberculosis H37Rv $a h p C^{+}$and $a h p C:: \mathrm{Km}^{\mathrm{r}}$ were allowed to reach stationary phase and then used to infect J774A macrophages at an m.o.i. of 10:1 in the presence or absence of IFN $\gamma$ and LPS. No differences in survival were observed within the first 3 days of infection (data not shown). However, after 7 days of infection, the survival of the mutant and the wild-type differed by one order of magnitude in resting macrophages (Fig. 4, filled bars), indicating a contribution of $a h p C$ to innate defences in unstimulated macrophages, although our data cannot exclude a role for $\mathrm{AhpC}$ under some untested, immune phase conditions. The difference between $a h p C^{+}$and $a h p C:: \mathrm{Km}^{\mathrm{r}}$ strains was abrogated in macrophages stimulated with IFN $\gamma$ and LPS (Fig. 4, open bars). In conclusion, $a b p C$ plays a role in M. tuberculosis survival in macrophages.
However, its action seems to be either independent of IFN $\gamma$-induced effectors (e.g. NO; compare results with NO donors in Fig. 2), or its contribution is masked by additional cidal mechanisms in activated macrophages or by activation of additional defence mechanisms in $M$. tuberculosis.

\section{Conclusions}

Our results indicate that an intact $a h p C$ gene is preserved in M. tuberculosis, despite the loss of its activator oxyR, because it does confer a selective advantage under a subset of circumstances encountered by the organism during infection as modelled in this study. It is also likely that KatG and AhpC have partially overlapping defence activities, and that they undergo stage-specific and/or tissue-specific expression with compensatory activities, as previously noted (Dhandayuthapani et al., 1996; Sherman et al., 1996; Heym et al., 1997; Master et al., 2001; Musser, 1995; Wallis et al., 1999, 2000). Thus, the absence of oxyR (Deretic et al., 1995, 1997), the silencing of $a h p C$ (Springer et al., 2001), and its differential expression and infection-stage-specific induction (Springer et al., 2001) most likely reflect adaptations of $M$. tuberculosis to various aspects of its infectious cycle. For example, upon transmission to a new host or possibly during initial stages of reactivation from latent infection, the probably stationary-phase $M$. tuberculosis infects naïve, resting monocytes where $a h p C$ may play a role in resistance to the very early, innate cidal mechanisms in macrophages (as shown in Fig. 4.). Once IFN $\gamma$ and other protective cytokines become available, $a h p C$ may play a lesser role, as indicated by the loss of differential survival between $a h p C^{+}$and $a h p C:: \mathrm{Km}^{\mathrm{r}}$ cells in macrophages, although our studies do not permit us to rule out a role for AhpC under some other, untested conditions operating during the adaptive immunity stage of the host response to mycobacterial infection. We propose that, at the very minimum, $a h p C$ plays a role of an early sentinel, as the tubercle bacillus comes out of the stationary phase during dormancy (latent infection) upon reactivation or upon transmission to a new host.

\section{ACKNOWLEDGEMENTS}

This work was supported by NIH grant AI42999. 


\section{REFERENCES}

Akaki, T., Tomioka, H., Shimizu, T., Dekio, S. \& Sato, K. (2000). Comparative roles of free fatty acids with reactive nitrogen intermediates and reactive oxygen intermediates in expression of the anti-microbial activity of macrophages against Mycobacterium tuberculosis. Clin Exp Immunol 121, 302-310.

Aslund, F., Zheng, M., Beckwith, J. \& Storz, G. (1999). Regulation of the OxyR transcription factor by hydrogen peroxide and the cellular thiol-disulfide status. Proc Natl Acad Sci USA 96, 6161-6165.

Baillon, M. L., van Vliet, A. H., Ketley, J. M., Constantinidou, C. \& Penn, C. W. (1999). An iron-regulated alkyl hydroperoxide reductase $(\mathrm{AhpC})$ confers aerotolerance and oxidative stress resistance to the microaerophilic pathogen Campylobacter jejuni. J Bacteriol 181, 4798-4804.

Bryk, R., Griffin, P. \& Nathan, C. (2000). Peroxynitrite reductase activity of bacterial peroxiredoxins. Nature 407, 211-215.

Bsat, N., Herbig, A., Casillas-Martinez, L., Setlow, P. \& Helmann, J. D. (1998). Bacillus subtilis contains multiple Fur homologues: identification of the iron uptake (Fur) and peroxide regulon (PerR) repressors. Mol Microbiol 29, 189-198.

Chauhan, R. \& Mande, S. C. (2001). Characterization of the Mycobacterium tuberculosis H37Rv alkyl hydroperoxidase AhpC points to the importance of ionic interactions in oligomerization and activity. Biochem J 354, 209-215.

Chen, L., Xie, Q. W. \& Nathan, C. (1998). Alkyl hydroperoxide reductase subunit $\mathrm{C}(\mathrm{AhpC})$ protects bacterial and human cells against reactive nitrogen intermediates. Mol Cell 1, 795-805.

Christman, M. F., Morgan, R. W., Jacobson, F. S. \& Ames, B. N. (1985). Positive control of a regulon for defenses against oxidative stress and some heat-shock proteins in Salmonella typhimurium. Cell 41, 753-762.

Cole, S. T. (1998). The Mycobacterium leprae genome project. Int J Lepr Other Mycobact Dis 66, 589-591.

Cooper, A. M., Segal, B. H., Frank, A. A., Holland, S. M. \& Orme, I. M. (2000). Transient loss of resistance to pulmonary tuberculosis in $\mathrm{p} 7^{(\text {phox-/-) }}$ mice. Infect Immun 68, 1231-1234.

Darrah, P. A., Hondalus, M. K., Chen, Q., Ischiropoulos, H. \& Mosser, D. M. (2000). Cooperation between reactive oxygen and nitrogen intermediates in killing of Rhodococcus equi by activated macrophages. Infect Immun 68, 3587-3593.

Deretic, V., Philipp, W., Dhandayuthapani, S., Mudd, M. H., Curcic, R., Garbe, T., Heym, B., Via, L. E. \& Cole, S. T. (1995). Mycobacterium tuberculosis is a natural mutant with an inactivated oxidative-stress regulatory gene: implications for sensitivity to isoniazid. Mol Microbiol 17, 889-900.

Deretic, V., Song, J. \& Pagan-Ramos, E. (1997). Loss of $o x y R$ in Mycobacterium tuberculosis. Trends Microbiol 5, 367-372.

Dhandayuthapani, S., Zhang, Y., Mudd, M. H. \& Deretic, V. (1996). Oxidative stress response and its role in sensitivity to isonicotinic acid hydrazide in Mycobacterium species: characterization and inducibility of $a h p C$ by peroxides in $M$. smegmatis and lack of expression in M. aurum and M. tuberculosis. J Bacteriol 178, 3641-3649.

Dubrac, S. \& Touati, D. (2000). Fur positive regulation of iron superoxide dismutase in Escherichia coli: functional analysis of the $\operatorname{sodB}$ promoter. J Bacteriol 182, 3802-3808.

Hassett, D. J., Howell, M. L., Ochsner, U. A., Vasil, M. L., Johnson, Z. \& Dean, G. E. (1997). An operon containing fum $C$ and $\operatorname{sod} A$ encoding fumarase $\mathrm{C}$ and manganese superoxide dismutase is controlled by the ferric uptake regulator in Psendomonas aeruginosa: fur mutants produce elevated alginate levels. $J$ Bacteriol 179, 1452-1459.

Heym, B., Zhang, Y., Poulet, S., Young, D. \& Cole, S. T. (1993). Characterization of the $k a t G$ gene encoding a catalase-peroxidase required for the isoniazid susceptibility of Mycobacterium tuberculosis. J Bacteriol 175, 4255-4259.

Heym, B., Stavropoulos, E., Honore, N., Domenech, P., SaintJoanis, B. T., Wilson, M., Collins, D. M., Colston, M. J. \& Cole, S. T. (1997). Effects of overexpression of the alkyl hydroperoxide reductase $\mathrm{AhpC}$ on the virulence and isoniazid resistance of Mycobacterium tuberculosis. Infect Immun 65, 1395-1401.

Hillas, P. J., del Alba, F. S., Oyarzabal, J., Wilks, A. \& Ortiz De Montellano, P. R. (2000). The AhpC and AhpD antioxidant defense system of Mycobacterium tuberculosis. J Biol Chem 275, 18801-18809.

Jacobson, F. S., Morgan, R. W., Christman, M. F. \& Ames, B. N. (1989). An alkyl hydroperoxide reductase from Salmonella typhimurium involved in the defense of DNA against oxidative damage. J Biol Chem 264, 1488-1496.

Jiang, Z.-Y., Hunt, J. V. \& Wolff, S. P. (1992). Ferrous ion oxidation in the presence of xylenol orange for detection of lipid hydroperoxide in low-density lipoprotein. Ann Biochem 202, 384-389.

Karupiah, G., Hunt, N. H., King, N. J. \& Chaudhri, G. (2000). NADPH oxidase, Nramp1 and nitric oxide synthase 2 in the host antimicrobial response. Rev Immunogenet 2, 387-415.

Lee, H. S., Lee, Y. S., Kim, H. S., Choi, J. Y., Hassan, H. M. \& Chung, M. H. (1998). Mechanism of regulation of 8-hydroxyguanine endonuclease by oxidative stress: roles of FNR, ArcA, and Fur. Free Radic Biol Med 24, 1193-1201.

Li, Z., Kelley, C., Collins, F., Rouse, D. \& Morris, S. (1998). Expression of kat $G$ in Mycobacterium tuberculosis is associated with its growth and persistence in mice and guinea pigs. J Infect Dis 177, 1030-1035.

Magliozzo, R. S. \& Marcinkeviciene, J. A. (1997). The role of $\mathrm{Mn}$ (II)-peroxidase activity of mycobacterial catalase-peroxidase in activation of the antibiotic isoniazid. J Biol Chem 272, 8867-8870.

Manca, C., Paul, S., Barry, C. E., 3rd, Freedman, V. H. \& Kaplan, G. (1999). Mycobacterium tuberculosis catalase and peroxidase activities and resistance to oxidative killing in human monocytes in vitro. Infect Immun 67, 74-79.

Master, S., Zahrt, T. C., Song, J. \& Deretic, V. (2001). Mapping of Mycobacterium tuberculosis kat $G$ promoters and their differential expression in infected macrophages. J Bacteriol 183, 4033-4039.

Middlebrook, G. \& Kohn, M. L. (1953). Some observations on the pathogenicity of isoniazid resistant variants of the tubercle bacilli. Science 118, 297-299.

Mitchison, D. A., Selkon, J. B. \& Lloyd, J. (1963). Virulence in the guinea pig, susceptibility to hydrogen peroxide, and catalase activity of isoniazid-sensitive tubercle bacilli from South Indian and British patients. J Pathol Bacteriol 86, 377-386.

Morse, W. C., Weiser, O. L., Kuhns, D. M., Fusillo, M., Dail, M. C. \& Evans, J. R. (1954). Study of the virulence of isoniazid-resistant tubercle bacilli in guinea pigs and mice. Am Rev Tuberc 69, 464-468.

Musser, J. M. (1995). Antimicrobial agent resistance in mycobacteria: molecular genetic insights. Clin Microbiol Rev 8, 496-514.

Nakata, N., Matsuoka, M., Kashiwabara, Y., Okada, N. \& Sasakawa, C. (1997). Nucleotide sequence of the Mycobacterium leprae katG region. J Bacteriol 179, 3053-3057. 
Nathan, C. \& Shiloh, M. U. (2000). Reactive oxygen and nitrogen intermediates in the relationship between mammalian hosts and microbial pathogens. Proc Natl Acad Sci US A 97, 8841-8848.

Niederhoffer, E. C., Naranjo, C. M., Bradley, K. L. \& Fee, J. A. (1990). Control of Escherichia coli superoxide dismutase ( $\operatorname{sodA}$ and $\operatorname{sod} B$ ) genes by the ferric uptake regulation $(f u r)$ locus. J Bacteriol 172, 1930-1938.

Nourooz-Zadeh, J., Tajaddini-Sarmadi, J. \& Wolff, S. P. (1994). Measurement of plasma hydroperoxide concentrations by the ferrous oxidation xylenol orange assay in conjunction with triphenylphosphine. Anal Biochem 220, 403-409.

Pagan-Ramos, E., Song, J., McFalone, M., Mudd, M. H. \& Deretic, V. (1998). Oxidative stress response and characterization of the oxyR-ahpC and furA-katG loci in Mycobacterium marinum. J Bacteriol 180, 4856-4864.

Paziak-Domanska, B., Klink, M., Jurkiewicz, M. \& Rudnicka, W. (2000). Production of reactive nitrogen and oxygen intermediates in human granulocytes and monocytes during internalization of live BCG bacilli. Med Dosw Mikrobiol 52, 353-360.

Sherman, D. R., Mdluli, K., Hickey, M. J., Arain, T. M., Morris, S. L., Barry, C. E. \& Stover, C. K. (1996). Compensatory ahpC gene expression in isoniazid-resistant Mycobacterium tuberculosis. Science 272, 1641-1643.

Shiloh, M. U. \& Nathan, C. F. (2000). Reactive nitrogen intermediates and the pathogenesis of Salmonella and mycobacteria. Curr Opin Microbiol 3, 35-42.

Springer, B., Master, S., Sander, P. \& 7 other authors (2001). Silencing the oxidative stress response in Mycobacterium tuberculosis: Expression patterns of $a h p C$ in virulent and avirulent strains and the effect of $a h p C$ inactivation. Infect Immun $\mathbf{6 9}$, 5967-5973.

Sreevatsan, S., Pan, X., Zhang, Y., Deretic, V. \& Musser, J. M. (1997). Analysis of the $o x y R-a h p C$ region in isoniazid-resistant and -susceptible Mycobacterium tuberculosis complex organisms recovered from diseased humans and animals in diverse localities. Antimicrob Agents Chemother 41, 600-606.

Storz, G. \& Altuvia, S. (1994). OxyR regulon. Methods Enzymol 234, 217-223.

Tardat, B. \& Touati, D. (1993). Iron and oxygen regulation of Escherichia coli MnSOD expression: competition between the global regulators Fur and ArcA for binding to DNA. Mol Microbiol 9, 53-63. van Vliet, A. H., Wooldridge, K. G. \& Ketley, J. M. (1998). Ironresponsive gene regulation in a Campylobacter jejuni fur mutant. J Bacteriol 180, 5291-5298.

van Vliet, A. H., Baillon, M. L., Penn, C. W. \& Ketley, J. M. (1999). Campylobacter jejuni contains two fur homologs: characterization of iron-responsive regulation of peroxide stress defense genes by the PerR repressor. J Bacteriol 181, 6371-6376.

Wallis, R. S., Patil, S., Cheon, S. H. \& 12 other authors (1999). Drug tolerance in Mycobacterium tuberculosis. Antimicrob Agents Chemother 43, 2600-2606.

Wallis, R. S., Perkins, M. D., Phillips, M. \& 10 other authors (2000). Predicting the outcome of therapy for pulmonary tuberculosis. Am J Respir Crit Care Med 161, 1076-1080.

Wengenack, N. L., Jensen, M. P., Rusnak, F. \& Stern, M. K. (1999). Mycobacterium tuberculosis KatG is a peroxynitritase. Biochem Biophys Res Commun 256, 485-487.

Wilson, T., de Lisle, G. W., Marcinkeviciene, J. A., Blanchard, J. S. \& Collins, D. M. (1998). Antisense RNA to $a h p C$, an oxidative stress defence gene involved in isoniazid resistance, indicates that AhpC of Mycobacterium bovis has virulence properties. Microbiology 144, 2687-2695.

Wilson, T. M., de Lisle, G. W. \& Collins, D. M. (1995). Effect of inhA and kat $G$ on isoniazid resistance and virulence of $\mathrm{Myco-}$ bacterium bovis. Mol Microbiol 15, 1009-1015.

Wolff, S. P. (1994). Ferrous ion oxidation in the presence of ferric iron indicator xylenol orange for measurement of hydroperoxides. Methods Enzymol 223, 182-189.

Yu, K., Mitchell, C., Xing, Y., Magliozzo, R. S., Bloom, B. R. \& Chan, J. (1999). Toxicity of nitrogen oxides and related oxidants on mycobacteria: M. tuberculosis is resistant to peroxynitrite anion. Tuber Lung Dis 79, 191-198.

Zahrt, T. C. \& Deretic, V. (2002). Reactive nitrogen and oxygen intermediates and bacterial defenses: unusual adaptations in Mycobacterium tuberculosis. Antioxid Redox Signal 4, 141-159.

Zahrt, T. C., Song, J., Siple, J. \& Deretic, V. (2001). Mycobacterial FurA is a negative regulator of catalase-peroxidase gene kat $G$. Mol Microbiol 39, 1174-1185.

Zheng, M., Doan, B., Schneider, T. D. \& Storz, G. (1999). OxyR and SoxRS regulation of fur. J Bacteriol 181, 4639-4643.

Received 22 March 2002; revised 22 June 2002; accepted 26 July 2002 